\title{
Chemical pretreatment of agricultural feedstock for enhanced production of cellulase by mutant fungus, Aspergillus niger
}

\begin{abstract}
In this study the effectiveness of chemical pretreatment on natural lignocelluloses for enhanced production of cellulase by mutant fungal culture, Aspergillus niger was investigated. Locally available agricultural feedstock's namely rice bran, black gram husk, groundnut shells, sawdust, sugarcane bagasse, red gram husk and dry leaves were pretreated with hydrogen chloride, sodium hydroxide and hydrogen peroxide chemicals with different concentrations. The cellulolytic activity of Aspergillus niger was assessed by congo-red plate screening. The fungi genetically mutated with Ethyl methane sulfapnate was produced higher titers of cellulases (Fpase 4.90IU, CMCase $1.608 \mathrm{IU}$, and $\beta$-glucosidase, $0.64 \mathrm{IU})$. The cellulolytic activity of fungal mutant grown on $\mathrm{NaOH}$ pretreated lignocelluloses showed elevated levels of FPase (14.89IU) and CMCase (18.60IU) on sugarcane bagasse and $\beta$-glucosidase activity (0.52IU) on saw dust respectively. Compared to acid and alkali treatment considerable hiper production of cellulase (Fpase-20.46 CMCase-17.60, $\beta$-glucosidase 1.73IU) was achieved Aspergillus niger grown in medium sugarcane bagasse treated with $5 \%$ hydrogen peroxide as substrate.
\end{abstract}

Keywords: agricultural feedstocks, chemical pretreatment, aspergillus niger mutation studies, cellulase production
Volume I Issue I - 2016

\author{
Narasimha G, Reddi Pradeep M, Sridevi A \\ Department of Virology, Sri Venkateswara University, India
}

Correspondence: G Narasimha,Applied Microbiology Laboratory, Department of Virology, Sri Venkateswara University, Tirupati-5 I7502, India, Email gnsimha I23@rediffmail.com

Received: August 12, 2016 | Published: October 05, 2016

\section{Introduction}

Long-term economic and environmental concerns have resulted in a great amount of research in past couple of decades on renewable source of liquid fuels to replace fossil fuels. The lignocellulosic biomass is most abundant available organic source in the biosphere mainly composed of cellulose, hemicellulose, and lignin that are strongly intermeshed and chemically bonded by non-covalent interactions via covalent crosslinkages. ${ }^{1,2}$ Cellulose-rich plant biomass is one of the foreseeable and sustainable sources of fuel, animal feed and feed stock for chemical synthesis. ${ }^{3}$ The utilization of cellulosic biomass continues to be a subject of worldwide interest in view of fast depletion of our oil reserves and food shortages. ${ }^{4}$ Cellulose serves as a vast reservoir of glucose residues linked by $\beta-1,4$ glycosidic bonds. The major constituents of lignocellulosic materials are cellulose, hemicellulose and lignin which make it very hard for cellulolytic organisms to utilize this material. Therefore, efficient pretreatment method is required to enhance enzymatic sachharifiaction. ${ }^{5}$ The ultimate goal of the pretreatment methods is to remove lignin content from agricultural feedstock and to decrease their cellulose crystallinity. ${ }^{6}$ Many pretreatment methods have been practiced over the years to in addition to this process, the cellulolytic enzymes have also been exploited for commercial applications like malting, wood processing, preparation of denim fabrics in textile industries, maceration of protoplasts from plant tissues and deinking process in recycling of printed papers. But the saccharification process has not reached to the level of commercialization in certain applications pertaining to production of befouls. One of the primary challenges for process commercialization is the development of costeffective pretreatment technologies for lignocellulosic feedstock's. ${ }^{2,6,7}$ Pretreatment is necessary to increase the accessibility of cellulose in lignocellulosic biomass to facilitate enzymatic hydrolysis. In view of biotechnological importance of cellulases, the present study was focused on enhanced production of cellulases by genetically altered fungal strain, Aspergillus niger grown on pretreated lignocellulosic substrates in submerged fermentation.

\section{Materials and methods}

\section{Microorganisms}

The fungal culture, Aspergillus niger used in this study was isolated from soil contaminated with effluents of cotton ginning mill Narasimha et al. ${ }^{8}$

\section{Screening of Aspergillus niger for cellulase production}

The cellulolytic property of Aspergillus niger was primarily screened by plate screening method. For this, Czapek-Dox agar medium amended with $1 \%$ carboxy methyl cellulose (CMC) and the plates were incubated for 3 days at $50^{\circ} \mathrm{C}$ in an oven. After incubation plates were stained with $1 \%$ Congo-red solution, followed by destaining with $1 \mathrm{M} \mathrm{NaCl}$ solution for 15 minutes.

\section{Mutation studies}

The spore suspension of the A. niger was subjected to chemical mutagen ethyl methane sulfonate (EMS) treatment. Four millilitre of spore suspension was added to EMS solution $(0.1 \mathrm{mg} / \mathrm{ml})$ and the reaction was allowed to proceed. Two millilitres of this solution was taken at different time intervals of $30,60,90,120,150,180$ and 210 minutes and centrifuged for $10 \mathrm{~min}$ at $5000 \mathrm{rpm}$ centrifugation (Thermo Scientific) and supernatant solution was decanted. Fungal spores was washed with sterile water and resuspended in phosphate 
buffer. The samples were serially diluted in the same buffer and plated on Czapek-Dox agar medium and incubated at room temperature. After incubation mutant fungi was selected based on plates showing less than $1 \%$ survival rate.

\section{Preparation of fungal spore inoculum for cellulase production}

The mutant Aspergillus niger grown on Czapek-Dox agar slants at room temperature for 7 days. Fungal spore inoculum density prepared $\left(2 \mathrm{X} 10^{6}\right.$ spores) for cellulase production.

Lignocellulosic substrates: The lignocellulosic substrates, ricebran, black gram, groundnut shells, peaseed husk, sawdust, sugarcane bagasse, dry leaves, red gram were collected from rural areas of Tirupati, Andhra Pradesh, India.

Acid treatment $(\mathrm{HCl})$ : The lignocellulosic substrates were soaked individually in $0.1 \mathrm{M} \mathrm{HCl}$ in the ratio $1: 10(\mathrm{~W} / \mathrm{V}$ ) for 60 minutes at room temperature. The substrates were washed with distilled water for removal of chemicals and autoclaved at $12^{\circ} \mathrm{C}$ for one hour. The acid treated substrates were filtered for free of fibers and neutralized by washing with dilute aqueous sodium hydroxide. The pre-treated substrates were washed with double distilled water until the filtrate becomes neutral. The substrates were dried at $60^{\circ} \mathrm{C}$ for $12 \mathrm{~h}$ in hot air oven and used for further studies.

Alkali treatment $(\mathbf{N a O H})$ : Lignocelluloses treated with $0.1 \mathrm{M}$ $\mathrm{NaOH}$ solution in the ratio $1: 10(\mathrm{~W} / \mathrm{V})$ for 60 minutes at room temperature and the substrates were washed with distilled water, autoclaved at $12^{\circ} \mathrm{C}$ for one hour. After incubation the treated substrates were washed with double distilled water until the wash water turned to become neutral $\mathrm{pH}$. The substrates were dried at $60^{\circ} \mathrm{C}$ for $12 \mathrm{~h}$ in an oven.

Hydrogen peroxide treatment $\left(\mathrm{H}_{2} \mathrm{O}_{2}\right)$ : The lignocellulosics were treated with hydrogen peroxide $\left(\mathrm{H}_{2} \mathrm{O}_{2}\right)$ with concentrations of 5 and 10 percentage respectively. The $\mathrm{pH}$ of the solution was adjusted to 11.5 and stirred gently at room temperature $25^{\circ} \mathrm{C}$ for $20 \mathrm{hrs}$. The contents were filtered and washed with distilled water until $\mathrm{pH}$ turns to neutral. The treated samples were dried at $110^{\circ} \mathrm{C}$ for overnight in an oven.

\section{Cellulase assay}

The pretreated lignocellulosic substrates were used as carbon source for cellulase production by mutant fungal strain Asperrgillus niger .The filter paperase, carboxymethyl cellulase and $\beta$-glucosidasea activities were assayed..$^{9,10}$ Enzyme activities were expressed as units. One unit of cellulase is corresponded to $1 \mu \mathrm{mol}$ of glucose released per min by $1 \mathrm{ml}$ of the culture broth.

\section{Results and discussion}

Selective and effective separation of fractions present in lignocellulose biomass with pre-treatment is of great interest today. The by-products obtained during hydrolysis of biomass may affect the fermentation yield and also valuable sources are lost if other fractions are partially hydrolyzed. Hence pre-treatment techniques either with physical, chemical and biological methods are necessary. But enzymes cannot effectively convert lignocelluloses to fermentable sugars without chemical pre-treatment. Hence in this study cellulase production with mutant A.niger strain grown on chemically pretreated lignocellulosic substrates was investigated.

\section{Screening of Aspergillus niger for cellulase production}

Cellulolytic activity of fungal culture, Aspergillus niger was determinated by congo-red agar plate screening assay. Formation of a clear yellow colored zone around the fungal culture is an indication of hydrolysis corboxy methyl cellulose by fungal culture (Figure 1).

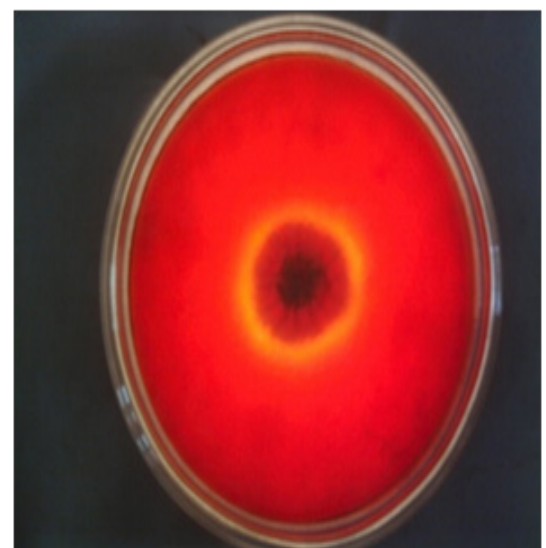

Figure I Screening of cellulolytic activity of Aspergillus niger.

\section{Cellulase production by wild and mutant Aspergillus niger}

Cellulase activity of wild and mutant fungal strains (GNEM1GNEM10) were shown in Figure 2. Among the ten EMS mutants, $\mathrm{GNEM}_{7}$ showed maximum Fpase 4.90 IU, CMCase 1.608 IU, $\beta$-glucosidase $0.64 \mathrm{IU}$, which were $204 \%, 502 \%$ and $236 \%$ higher than the parent strain activities respectively. This strain was used for further studies.

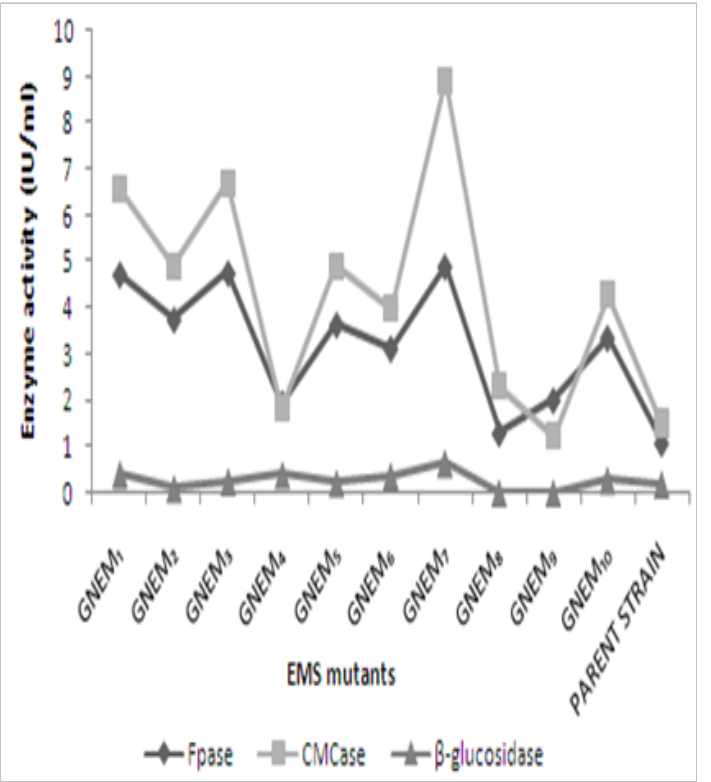

Figure 2 Cellulolytic activity of EMS (ethyl methane sulfonate) wild and mutant Aspergillus niger.

\section{Cellulase production by A.niger grown on alkali pre- treated lignocelluloses}

Alkali pre-treatment involves the application of alkaline solutions like $\mathrm{NaOH}$ or $\mathrm{KOH}$ to remove lignin and a part of the hemicelluloses, 
and efficiently increase the accessibility of enzyme. The alkali pretreatment can result in a sharp increase in saccharification yields. This study also evaluated the cellulolytic activity of EMS mutant $\left(\mathrm{GNEM}_{7}\right)$ on $\mathrm{NaOH}$ pretreated lignocelluloses (Figure 3). The mutant strain $\mathrm{GNEM}_{7}$ exihibited elevated levels of FPase (14.89IU) and CMCase (18.60IU) on pretreated sugarcane bagasse in the medium. Maximum $\beta$-glucosidase activity was observed (0.52IU) when saw dust as carbon source. Earlier studies revealed that maximum cellulase was obtained with $\mathrm{NaOH}$ treated rice straw and baggage. ${ }^{11}$ Maximum cellulase production was found in alkali-treated soybean hulls with CMCase, FPase and $\beta$-glucosidase yields of $9.91 \pm 0.04,6.20 \pm 0.13$ and $5.69 \pm 0.29 \mathrm{U} / \mathrm{g}$, respectively. ${ }^{12}$ The cellulase yield was reached maximum with Fpase, CMCase were $9.3,8.5 \mathrm{U} / \mathrm{ml}$ on $1 \%$ alkali treated ricebran and $\beta$-glucosidase was $1.14 \mathrm{U} / \mathrm{ml}$ on $0.5 \%$ treated ricebran respectively. ${ }^{13}$ Similarly cellulase activity increased with three times higher than the natural substrate using pretreated fiber. ${ }^{12,14}$ The alkali treated saw dust yielded higher FPase $(6.3 \mathrm{U} / \mathrm{ml})$, CMCase $(7.2 \mathrm{U} / \mathrm{ml})$ at 7 -day incubation and rice bran produced $\beta$-glucosidase $(1.04 \mathrm{U} / \mathrm{ml})$ at 21 -day incubation. ${ }^{15}$

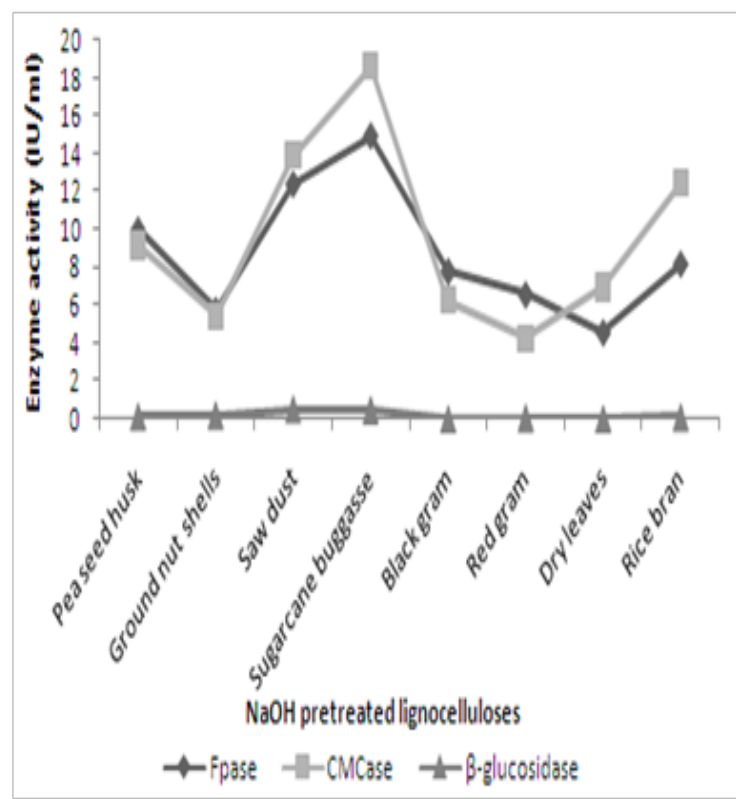

Figure 3 Cellulolytic activity of A.niger grown on $\mathrm{NaOH}$ pretreated lignocelluloses.

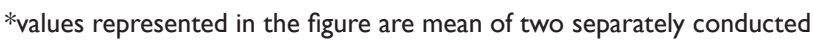
experiments

\section{Cellulase production by A.niger grown on acid pretrea- ted lignocelluloses}

Dilute acid pre-treatment predominantly affect hemicellulose with little impact on lignin degradation. Acid pre-treatment will solubilize the hemicellulose and makes the cellulose better accessible to enzymes. Acid pre-treatment is usually carried out using mineral acids like $\mathrm{HCl}$ and $\mathrm{H}_{2} \mathrm{SO}_{4}$. Following dilute acid treatment, the enzyme cellulase is needed for hydrolysis of the remaining carbohydrates in the treated biomass. The mutant strain $\left(\mathrm{GNEM}_{7}\right)$ exhibited higher titers of FPase (10.56IU) on sugarane bagasse, whereas $\beta$-glucosidase (1.760IU) production on pea seed husk in current work. The CMCase activity on pretreated saw dust is 11.4IU (Figure 4). Similar results were made with Aspergillus fumigatus grown on $\mathrm{HCl}$ pretreated wheat straw (Fpase-0.237IU $/ \mathrm{ml}$ and CMCase-0.674IU/ml). ${ }^{16}$ Kshirsagar et al. ${ }^{17}$ reported maximum reducing sugar yield $(359 \mathrm{mg} / \mathrm{g}$ dry biomass) from dilute acid pretreated rice straw after $72 \mathrm{~h}$ enzymatic hydrolysis. Cellulase production on modified wheat straw with $1 \%(\mathrm{v} / \mathrm{v})$ sulfuric acid, leading to $19.2 \mathrm{U} / \mathrm{g}$ FPase from solid stage fermentations using A. niger. ${ }^{18}$ The exo (Fpase) and endo (CMCase) glucanases found to be $0.089 \mathrm{U} / \mathrm{ml}$, and $1.023 \mathrm{U} / \mathrm{ml}$ in medium contains groundnut shells treated with $\mathrm{HCl}$ as substrate. ${ }^{19}$

*values represented in the figure are mean of two separately conducted experiments

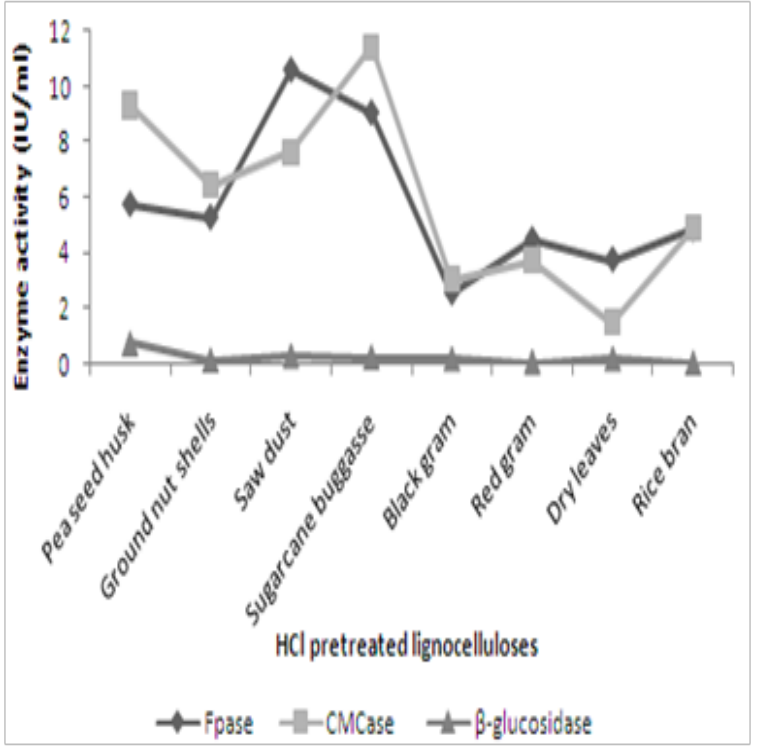

Figure 4 Cellulase production by mutant A.niger grown on IM HCl pretreated lignocelluloses.

*values represented in the figure are mean of two separately conducted experiments

\section{Cellulase production by A.niger grown on $\mathrm{H} 2 \mathrm{O} 2$ pre- treated lignocelluloses}

Oxidative pre-treatment involves the addition of an oxidising compound, like hydrogen peroxide or peracetic acid, to the biomass, which is suspended in water. This pre-treatment remove the hemicellulose and lignin to increase the accessibility of the cellulose. During oxidative pre-treatment electrophilic substitution, displacement of side chains, cleavage of alkyl aryl ether linkages or the oxidative cleavage of aromatic nuclei will take place ${ }^{20}$ and solubilize the lignin and loosen the lignocellulosic matrix to improve enzyme digestibility. ${ }^{21}$ Cellulolytic activity of mutant strain $\left(\mathrm{GNEM}_{7}\right)$ on 5 and $10 \%$ hydrogen peroxide treated lignocelluloses was shown in Figure $5 \mathrm{~A} \& 5 \mathrm{~B}$. Compared to acid and alkali treatments, higher cellulase activity obtained (Fpase-20.46 CMCase-17.60, $\beta$-glucosidase 1.73IU) in sugarcane bagasse, when treated with $5 \% \mathrm{H}_{2} \mathrm{O}_{2}$. Similar reports were made by Ikram et al. ${ }^{22}$ Filterpaperase, carboxy methyl cellulase activities were found to be $5.82 \mathrm{U} / \mathrm{ml}, 10.54 \mathrm{U} / \mathrm{ml}$ respectively on sugarcane bagasse treated with $5 \%$ hydrogen peroxide. Maximum $\beta$-glucosidase activity $1.73 \mathrm{IU}$ was measured on sawdust.

Lignocelluloses pretreated with $10 \%$ hydrogen peroxide resulted in elevated levels of enzyme production by mutant Aspergillus niger than the other pretreatments. The Fpase and $\beta$-glucosidase activities were $24.56 \mathrm{IU} / \mathrm{ml}$ and $1.73 \mathrm{IU} / \mathrm{ml}$ respectively obtained on saw dust and CMCase activity was $22.96 \mathrm{IU} / \mathrm{ml}$ on sugarcane bagasse. 


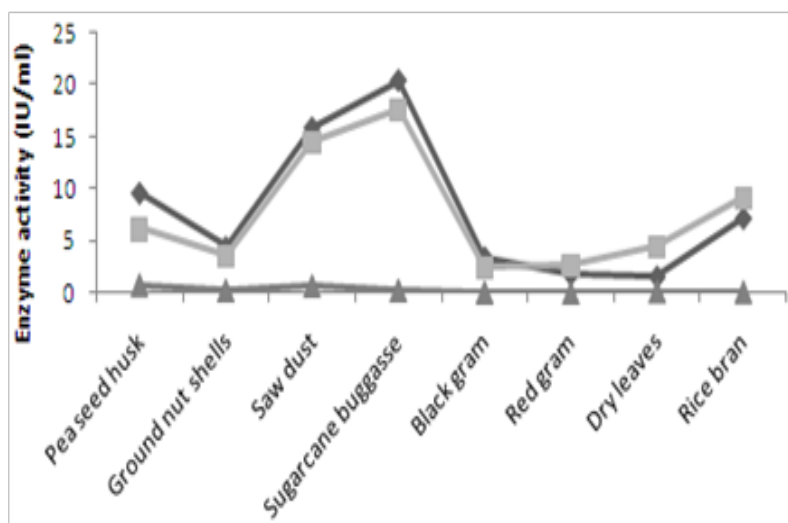

$\mathrm{H}_{2} \mathrm{O}_{2}(5 \%)$ pretreated lignocelluloses

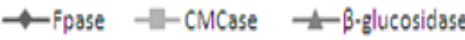

Figure 5A Cellulase production by A.niger grown on $10 \% \mathrm{H}_{2} \mathrm{O}_{2}$ pretreated lignocelluloses.

*values represented in the figure are mean of two separately conducted experiments

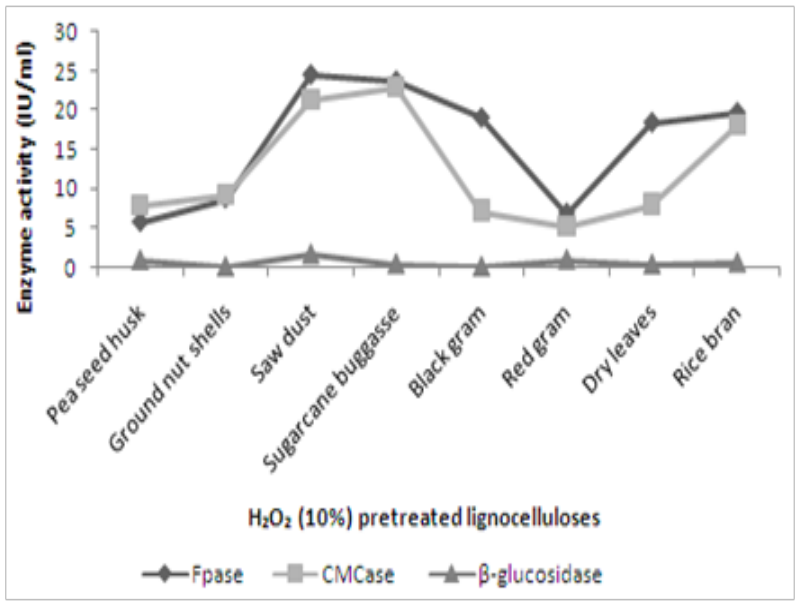

Figure 5B Cellulase production by A.niger grown on $10 \% \mathrm{H}_{2} \mathrm{O}_{2}$ pretreated lignocelluloses.

*values represented in the figure are mean of two separately conducted experiments

\section{Conclusion}

The present study clearly indicates that pretreatment of lignocelluloses with acid, alkali and peroxides enhanced the cellulase production by mutant fungal strain Aspergillus niger. Various lignocelluloses used in the study sugarcane bagassea and sawdust pretreated with $10 \%$ hydrogen peroxide showed the highest titers of cellulase production by mutant strain Aspergillus niger.

\section{Acknowledgements}

The authors were grateful to University Grants Commission (UGC), Government of India, and New Delhi for providing financial assistance to carry out the present work.

\section{Conflict of interest}

The author declares no conflict of interest.

\section{References}

1. Margeot A, Hahn Hagerdal BM, Edlund R, et al. New improvements for lignocellulosic ethanol. Curr Opin Biotechnol. 2009;20(3):372-380.

2. Lynd LR, weimer PJ, VanZyl WH, et al. Microbial cellulose utilization: fundamentals and biotechnology. Microbiol Mol Biol Rev. 2002;66(3):506-577.

3. Bhat MK, Bhat S. Cellulases and related enzymes in biotechnology. Biotechnology Adv. 2000;18(5):355-383.

4. Kuhad RC, Singh A, Eriksson KE. Microorganisms enzymes involved in the degradation of plant fiber cell walls. Advances in Biochemical Engineering Biotechnology. 1997;57:45-125.

5. Martín C, Galbe M, Nilvebrant NO, et al. Comparison of the fermentability of enzymatic hydrolyzates of sugarcane bagasse pretreated by steam explosion using different impregnating agents. Applied Biochemistry and Biotechnology. 2002;98(100):699-716.

6. Mosier N, Wyman C, Dale B, et al. Features of promising technologies for pretreatment of lignocellulose biomass. Bioresour Technol. 2005;96(6):673-686.

7. Wyman CE, Dale BE, Elander RT, et al. Coordinated development of leading biomass pretreatment technologies. Bioresour Technol. 2005;96(18):1959-1966.

8. Narasimha G, Babu GVAK, Rajasekhar Reddy B. Cellulolytic activity of fungal cultures isolated from soil contaminated with effluents of cotton ginning industry. J Env Biol. 1995;20(3):235-239.

9. Ghose TK. Measurement of cellulase activities. Pure \& Appl Chem. 1987;59(2):257-268.

10. Herr D. Secretion of cellulases and $\beta$-glucosides by Trichoderma viridae TTCC 1433 in submerged cultures on different substrates. Biotechnol Bioeng. 1979;21(8):1361-1363.

11. Banerjee UC. Production of $\beta$-glucosidase by Curvularia sp. Lett Appl Microbiol. 1990;10(5):197-199.

12. Aliyu Salihu, Olagunju Abbas, Abdullahi Balarabe Sallau, et al. Agricultural residues for cellulolytic enzyme production by Aspergillus niger: effects of pretreatment. Biotech. 2015;5(6):1101-1106.

13. Sridevi A, Narasimha G, Rajasekhar Reddy B. Production of cellulase by Aspergillus niger on natural and pretreated lignocellulosic wastes. The Internet Journal of Microbiology. 2008;1(1):1-8.

14. Umikalsom MS, Ariff AB, Shamsuddin $\mathrm{ZH}$, et al. Production of cellulase by a wild strain of Chaetomium globosum using delignified oil palm empty fruit bunch fiber as subsstrate. Appl Microbiol Biotechnol. 1997;47(5):590-595.

15. Sridevi A, Radha S, Narasimha G. Pretreatment of ricebran for effective production of cellulase by Aspergillus niger. International Journal of Pharma and Bio Sciences. 2011;2(4):B536-543.

16. Dahot MU, Hanif M. Production of cellulose on $\mathrm{HCl}$ pretreated wheat straw. Journal of Islamic academy of sciences. 1996;9(4):119-124.

17. Kshirsagar SD, Waghmare PR, Loni PC, et al. Dilute acid pretreatment of rice straw, structural characterization and optimization of enzymatic hydrolysis conditions by response surface methodology. RSC Advances. 2015;5:46525-46533.

18. Bansal N, Tewari R, Soni R, et al. Production of cellulases from Aspergillus niger NS-2 in solid state fermentation on agricultural and kitchen waste residues. Waste Manag. 2012;32:1341-1346. 
19. Ashish vyas, Deepak vyas, vyas KM. Production and optimization of cellulases on retreated ligno ground nut shells by Aspergillus terreus AV49. Journal scientific and industrial research. 2005;64:281-286.

20. Hon DNS, Shiraishi N. Wood and Cellulos Chemistry. 2nd ed. Dekker, New York: Kyoto University; 2001.
21. Martel P, Gould JM. Cellulose stability and delignification after alkaline hydrogen-peroxide treatment of straw. J Appl Polym Sci. 1990;39(3):707-714.

22. Ikram UL HAQ, Mohammad Moshin, et al. Sugarcane bagasse pretreatment: An attempt to enhance the production potential of cellulase by $\mathrm{Hu}$ micola insolens TAS-13. BIOKEMISTRI. 2006;18(2):83-85. 